\title{
Technical Note \\ The Feature of Ionospheric Mid-Latitude Trough during Geomagnetic Storms Derived from GPS Total Electron Content (TEC) Data
}

\author{
Na Yang ${ }^{1}$, Tao Yu ${ }^{1, *}$, Huijun Le ${ }^{2,3,4,5}$, Libo Liu ${ }^{2,3,4,5}$, Yang-Yi Sun ${ }^{1}$, Xiangxiang Yan ${ }^{1}$, Jin Wang ${ }^{1}$, \\ Chunliang Xia ${ }^{1}$, Xiaomin Zuo $^{1}$ and Guangliang Huang ${ }^{6}$
}

check for updates

Citation: Yang, N.; Yu, T.; Le, H.; Liu, L.; Sun, Y.-Y.; Yan, X.; Wang, J.; Xia,

C.; Zuo, X.; Huang, G. The Feature of Ionospheric Mid-Latitude Trough during Geomagnetic Storms Derived from GPS Total Electron Content (TEC) Data. Remote Sens. 2022, 14, 369. https://doi.org/10.3390/rs14020369 Academic Editor: Filomena Romano

Received: 15 December 2021

Accepted: 11 January 2022

Published: 13 January 2022

Publisher's Note: MDPI stays neutral with regard to jurisdictional claims in published maps and institutional affiliations.

Copyright: (C) 2022 by the authors. Licensee MDPI, Basel, Switzerland. This article is an open access article distributed under the terms and conditions of the Creative Commons Attribution (CC BY) license (https:// creativecommons.org/licenses/by/ $4.0 /)$.
1 Hubei Subsurface Multi-Scale Imaging Key Laboratory, Institute of Geophysics and Geomatics, China University of Geosciences, Wuhan 430074, China; yangna@cug.edu.cn (N.Y.); sunyy@cug.edu.cn (Y.-Y.S.); yanxx@cug.edu.cn (X.Y.); wangjin1221@whu.edu.cn (J.W.); xiachunliang@cug.edu.cn (C.X.); zuoxiaomin@cug.edu.cn (X.Z.)

2 Key Laboratory of Earth and Planetary Physics, Institute of Geology and Geophysics, Chinese Academy of Sciences, Beijing 100029, China; lehj@mail.iggcas.ac.cn (H.L.); liul@mail.iggcas.ac.cn (L.L.)

3 Innovation Academy for Earth Science, Chinese Academy of Sciences, Beijing 100029, China

4 Mohe National Observatory of Geology, Institute of Geology and Geophysics, Chinese Academy of Sciences, Beijing 100029, China

5 College of Earth and Planetary Sciences, University of the Chinese Academy of Sciences, Beijing 100049, China

6 School of Electrical and Information Engineering, Wuhan Institute of Technology, Wuhan 430205, China; glhuang@whu.edu.cn

* Correspondence: yutao@cug.edu.cn; Tel.: +027-87175251

\begin{abstract}
This study aims to investigate the features of the ionospheric mid-latitude trough over North America by using the MIT total electron content data obtained during three geomagnetic storms that occurred in August 2018, September 2017, and March 2015. The mid-latitude trough position sharply moves equatorward from the quiet-time subauroral latitude to mid-latitude with the decrease in SYM-H during geomagnetic storms. We find that the ionospheric behavior of TEC around the mid-latitude trough position displays three kinds of ionospheric storm effect: negative ionospheric storm effect, unchanged ionospheric behavior, and positive ionospheric storm effect. These ionospheric storm effects around the mid-latitude trough position are not always produced by the mid-latitude trough. The ionospheric storm effects produced by the mid-latitude trough are limited in the narrow mid-latitude trough regions, and are transmitted to other regions with the movement of the mid-latitude trough.
\end{abstract}

Keywords: ionospheric storm effect; mid-latitude trough; GPS TEC

\section{Introduction}

The mid-latitude trough is a nighttime plasma density depletion structure in the subauroral ionospheric $F$ region [1-3]. The depletion structure is typically close to 10 degrees wide in latitude, and appears at all longitudes in both the Northern and Southern Hemispheres [4,5]. The mid-latitude trough most frequently occurs in the nighttime. The mid-latitude trough structure is composed of three parts: a polar boundary, a trough minimum, and an equatorward boundary. The trough position refers to the trough's minimum position. The large density gradients on both boundaries of the mid-latitude trough can provoke severe amplitude and phase fluctuations of radio signals [3,6]; the fluctuations deteriorate the performance of navigation and positioning. For simplicity, the "trough" in this study refers to the mid-latitude trough.

Geomagnetic storms are major 'space weather' events. During geomagnetic storms, as geomagnetic activity levels increase, the trough shifts to lower latitudes due to the equatorward expansion of the auroral oval and the high-latitude convection [7-9]. Simultaneously, 
the equatorward displacement of the trough can cause obvious negative ionospheric storm effects, as found by various investigations [7,10-14]. During geomagnetic storms, the trough shifts to the mid-latitude ionosphere, thus resulting in the depletion of the local plasma density relative to the quiet-time level at the mid-latitude ionosphere-in other words, a negative ionospheric storm effect. Blagoveshchensky et al. [10] found that the formation of the trough across the oblique propagation path during the 28 April 2001 geomagnetic storm caused a decline in F2MOF (maximum observed frequency reflected from the F2 layer for the oblique incidence sounding signals) and F2LOF (lowest observed frequency reflected from the F2 layer for the oblique incidence sounding signals). Galav et al. [11] showed that the TEC data from Algonquin detected short-duration nighttime depletion caused by the trough during the May 2005 geomagnetic storm. Horvath and Lovell [12] reported that the earlier occurrence of the trough (relative to quiet time) over Goose Bay during the 15 May 2005 geomagnetic superstorm decreased the quiet-time electron densities significantly, and provoked an obvious negative ionospheric storm effect in the area of the trough $(\sim 5$ degrees of latitude). Liu et al. [14] studied the features of the mid-latitude ionospheric response to the 8 September 2017 geomagnetic storm, and found that a large TEC depletion region in the American sector was related to the equatorward movement of the trough. The geomagnetic storms can induce rapid changes in ionospheric electron density. The rapid changes have strong effects on navigation and positioning [12,15-17], due to the fact that a 1 TECU change in the TEC value is capable of inducing $0.16 \mathrm{~m}$ range error [18].

Previous studies suggest that the negative ionospheric storm effect is associated with the equatorward movement of the trough during geomagnetic storms. However, it is not clear whether the equatorward movement of the trough during geomagnetic storms is always accompanied by a negative ionospheric storm effect, or whether the negative ionospheric storm effect around the trough position is always related to the equatorward movement of the trough. The effect of the trough on the mid-latitude ionosphere during geomagnetic storms is examined in detail in this study. The study of such ionospheric behavior contributes to better understanding of the features of the trough and the mechanisms of the ionospheric storm effect associated with the trough during geomagnetic storms. In addition, this study contributes to understanding of the complex behavior and variation mechanisms of the nocturnal mid-latitude ionosphere during geomagnetic storms.

In this study, we selected and analyzed three typical intense geomagnetic storms that occurred during solar cycle 24 . The features of the trough during each storm were investigated by inspecting the spatial and temporal variations in TEC in the mid-latitude ionosphere. In the following section, the observation data and TEC analysis methods are described in detail. Section 3 presents results of the trough characteristics and the storm effects of TEC variations in the area of the trough during geomagnetic storms. These results are discussed in Section 4. The conclusions of the research are given in Section 5.

\section{Data and Methodology}

\subsection{Datasets}

GPS vertical TEC data released by the Madrigal database developed at the Haystack Observatory of Massachusetts Institute of Technology (MIT) were used to analyze and discuss the response of TEC to geomagnetic storms over North America. Detailed information on the TEC data and their derivation method are described by Rideout and Coster [19]. The spatial resolution of the TEC data is $1^{\circ} \times 1^{\circ}$ in geographical coordinates, and the temporal resolution is $5 \mathrm{~min}$. Figure 1 shows an example of the distribution of TEC data over North America during 06-07 UT (Universal Time) on 24 August 2018. Yang et al. [20] found that the trough mainly occurs in the range of $50^{\circ}-70^{\circ} \mathrm{N}$ magnetic latitude (MLAT). Thus, the TEC data in the range of $40^{\circ}-75^{\circ} \mathrm{N}$ MLAT and $-90^{\circ}$ to $-60^{\circ}$ E geographic longitude $(\mathrm{GLON})$ were selected to study the features of the trough during geomagnetic storms. The climatological features of the trough structure in the range of $-90^{\circ}$ to $-60^{\circ} \mathrm{E} \mathrm{GLON}$ have been studied and modeled by Le et al. [21]. 


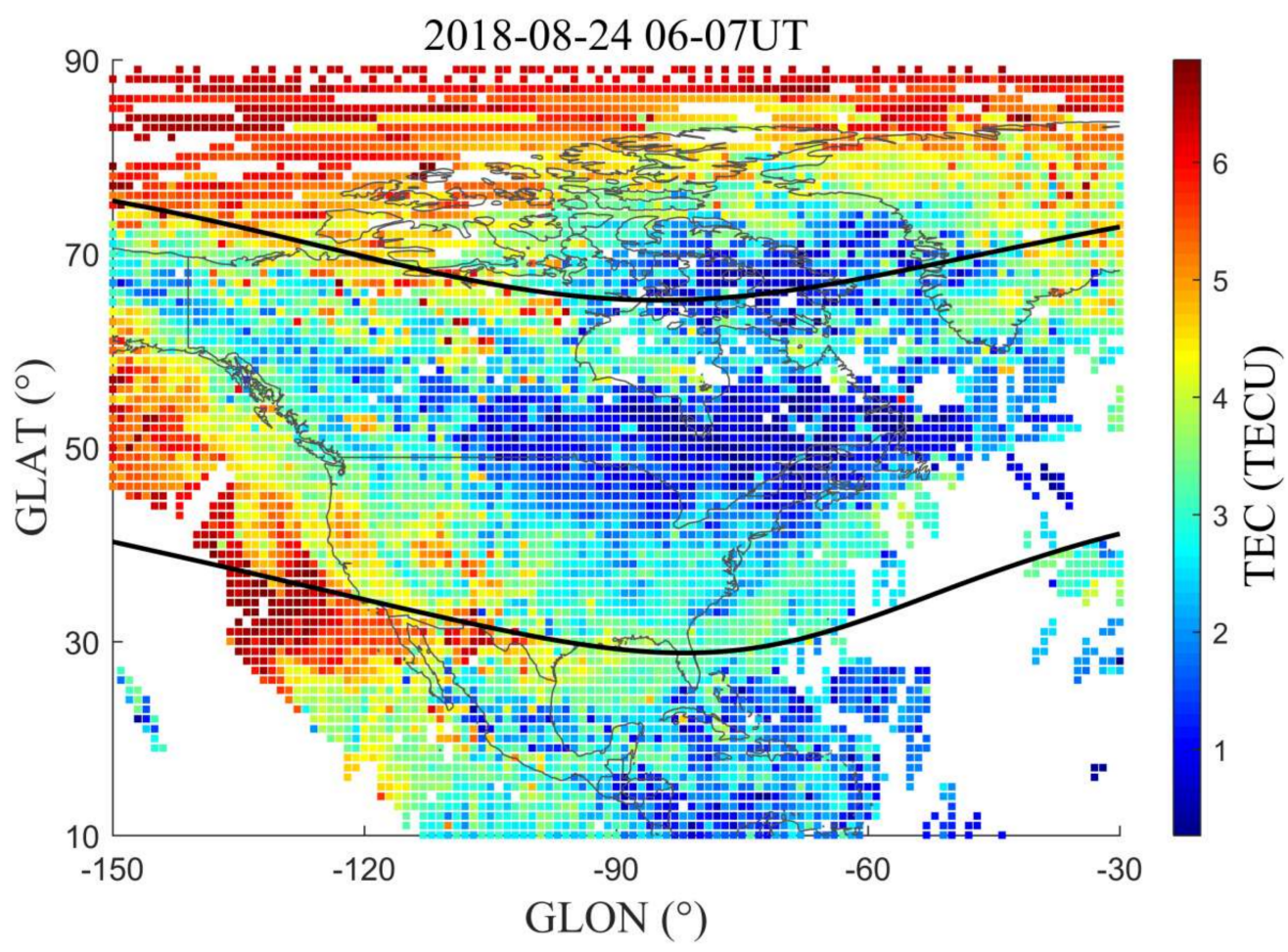

Figure 1. An example of the distribution of TEC data over North America during 06-07 UT on 24 August 2018. The upper and lower solid black lines represent $75^{\circ} \mathrm{N}$ and $40^{\circ} \mathrm{N}$ MLAT, respectively.

The SYM-H index, IMF Bz, Kp index, and solar flux index F10.7 data were extracted from the OMNIWeb database (http: / / omniweb.gsfc.nasa.gov (accessed on 1 November 2021)). The AE geomagnetic activity index data were downloaded from http:/ /wdc.kugi. kyoto-u.ac.jp/ (accessed on 1 November 2021).

\subsection{TEC Analysis Method}

We analyzed the TEC to study the trough over North America during geomagnetic storms. The analysis process was as follows: (1) The latitudinal TEC profile was defined as the average of the TEC values within the $-90^{\circ}$ to $-60^{\circ} \mathrm{E}$ GLON at each MLAT. (2) The local minimum of each latitudinal TEC profile was indicated. (3) The trough position was the TEC minimum in the area of 40-75 ${ }^{\circ}$ N MLAT. To determine the TEC changes for each storm, the TEC absolute deviation was defined as the difference between the TEC and the reference TEC. The reference was the average value of TEC during the period of 7 days before the storm [22].

In the present study, the effect of the storm-associated development of the trough on the nocturnal mid-latitude ionosphere during geomagnetic storms was analyzed almost exclusively for the main phase and the early recovery phase, due to the fact that the trough quickly recovered to the quiet-time subauroral latitude, with a typical timescale in the order of hours $[3,19]$.

\section{Results}

\subsection{August 2018 Storm}

\subsubsection{Geomagnetic Conditions}

The 2018 August storm was the third largest event during solar cycle 24 [23,24]. Figure 2 shows the IMF Bz and geophysical conditions during 24-26 August 2018. An initial phase of the storm occurred after 09 UT on 25 August. The main phase of the storm began at 16:05 UT on 25 August, as the SYM-H (Figure 2d) began to decrease. Around 07:12 UT on 26 August, the SYM-H (Figure 2d) reached the minimum of $-206 \mathrm{nT}$, indicating the end of the main phase. The IMF Bz turned northward at 09:50 UT on 26 August (Figure 2a). 
The corresponding AE (Figure 2b) and Kp (Figure 2c) indices gradually increased to more than $2000 \mathrm{nT}$ and 7, respectively. After 07 UT on 26 August, the SYM-H (Figure 2d) first increased quickly and then gradually recovered. The values of the F10.7 (Figure 2c) solar flux index were 74 solar flux units ( $\mathrm{sfu}$; $1 \mathrm{sfu}$ equals $10-22 \mathrm{~W} \mathrm{~m}^{-2} \mathrm{~Hz}^{-1}$ ), $73.1 \mathrm{sfu}$, and $72.6 \mathrm{sfu}$ on 24-26 August, respectively.

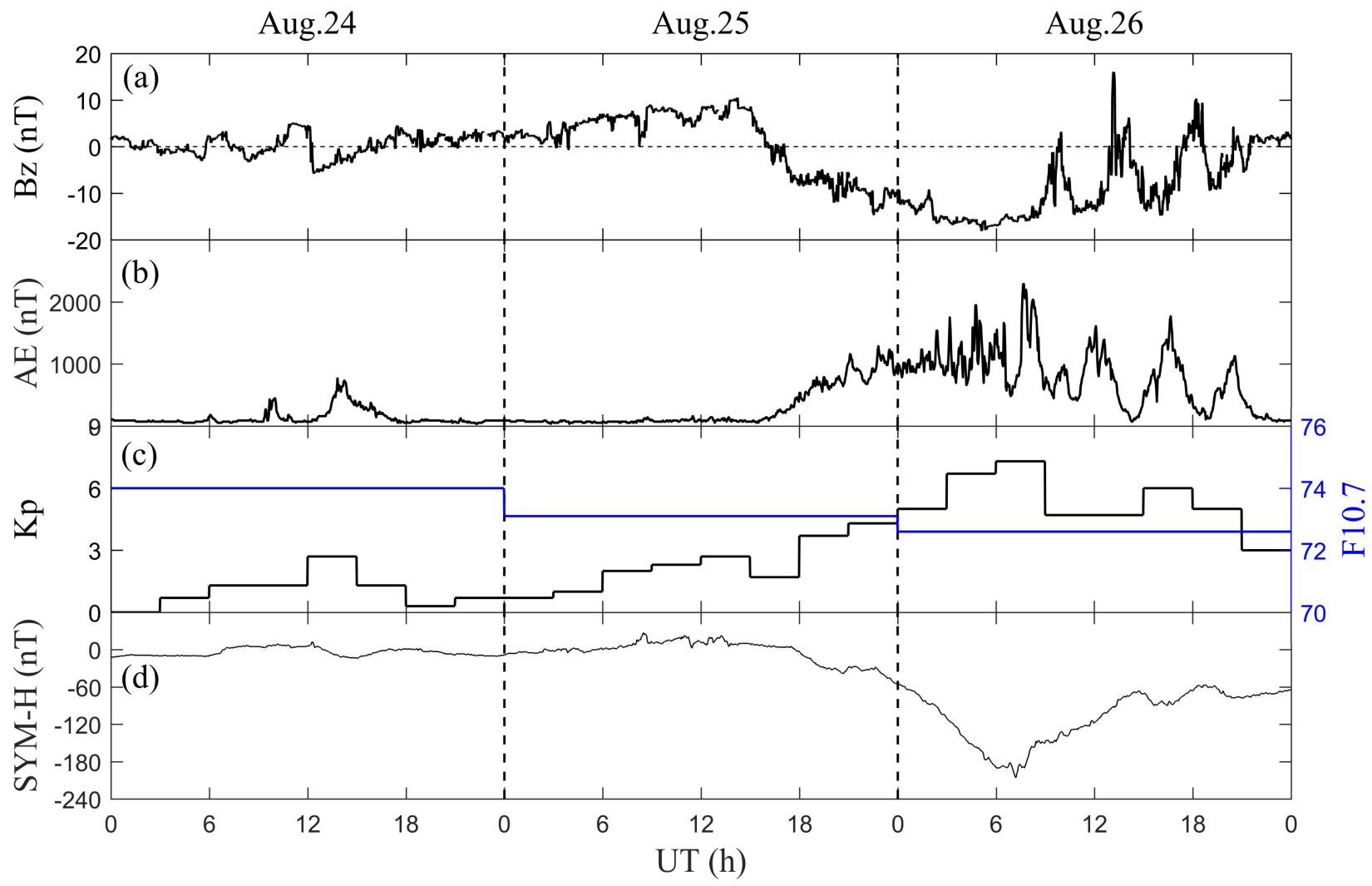

Figure 2. Time series of (a) IMF Bz, (b) AE index, (c) Kp index (dark line) and F10.7 (blue line), and (d) SYM-H index during the period of 24-26 August 2018.

\subsubsection{Ionospheric Storm Disturbance during the 2018 August Storm}

Figure 3 shows the ionospheric variations for the American sector during the 2018 August storm. Figure 3a displays the TEC distribution in UT-MLAT coordinates. During the quiet day on 24 August, the trough first appeared at 04 UT ( 23 LT) for the American sector, and then it slightly moved equatorward before $06 \mathrm{UT}$, and remained at $62^{\circ} \mathrm{N}$ in the post-midnight region (06-08 UT, 01-03 LT). After $08 \mathrm{UT}$, the trough shifted equatorward in the dawn sector. The trough position changed by $5^{\circ}$ in latitude during the quiet day. The TEC value in the trough gradually decreased with time, reaching a minimum value of less than 1.5 TECU during 05-09 UT ( 00-04 LT), and then gradually increased. During 01-12 UT on 25 August, before the storm, the trough first appeared at 05 UT ( 00 LT), and then remained at $62^{\circ} \mathrm{N}$ in the post-midnight region (05-07 UT, $\sim 00-02 \mathrm{LT}$ ). After $07 \mathrm{UT}$, the trough gradually moved equatorward in the dawn sector. During this period of time, the trough position changed by $\sim 3^{\circ}$ in latitude, which is slightly less than the change during the quiet day. The TEC value in the trough first decreased gradually with time, and then increased in the dawn sector, which is similar to that during the quiet day. During the storm's main phase, the trough first occurred at 22 UT ( 17LT) on 25 August, which is earlier than during the quiet day. Afterwards, the trough quickly moved equatorward with the rapid decrease in SYM-H. After 06 UT on 26 August, the SYM-H index gradually decreased, and then began to increase at 08 UT on 26 August, whereas the trough continued to move equatorward with a slower velocity until 09 UT. The equatorward movement of the trough stopped at 09 UT on 26 August; after that, the trough returned to a higher latitude 
and disappeared, which is related to the solar extreme ultraviolet (EUV) radiation [5,25]. During the main phase of this storm, the trough position changed by $\sim 20^{\circ}$, which is much larger than the change during the quiet day. The TEC value in the trough also showed similar temporal variation to that during the quiet day. The TEC value in the trough during 03-10 UT (22-05 LT) was between 1.5 and 2.5 TECU, which is larger than those at the same times during the quiet day.
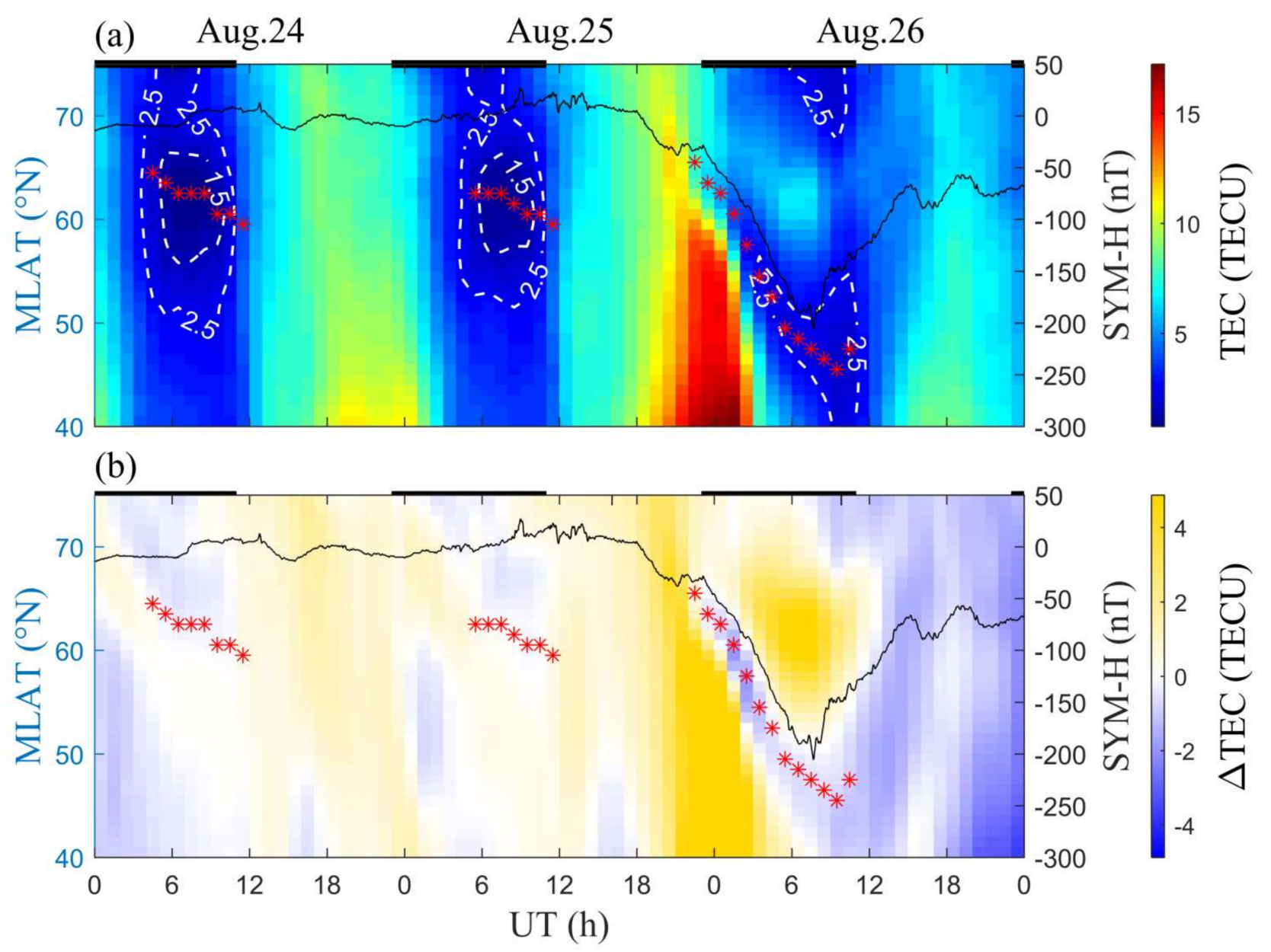

Figure 3. Ionospheric storm variations of (a) TEC and (b) TEC absolute deviations from the reference for the American sector during the 2018 August storm. The contour levels indicate the 1.5 and 2.5 TECU values. The red asterisks indicate the mid-latitude trough position. The black line shows the SYM-H variations. The local nighttime in the American sector is marked with thick black line segments.

Figure $3 b$ shows the TEC absolute deviations from the reference during the 2018 August storm. During 01-12 UT on 25 August, before the storm, the absolute deviation values of TEC in the area of the trough were near zero (indicated by white), meaning that the TEC value in the trough does not change relative to the quiet-time level. During the main phase, the absolute deviation of TEC in the area of the trough was negative (indicated by blue). It should be noted that the negative ionospheric storm effect aligns well with the trough position. Thus, the negative ionospheric storm effect is clearly related to the trough. The negative ionospheric storm effect caused by the trough was transmitted to lower latitudes through the equatorward movement of the trough. At the polar side of the trough, the absolute deviation value of TEC was positive. It is well known that the polar wall of the trough is formed by the auroral precipitation [3]. During the main phase, the AE index largely increased (see Figure 3b), which implies the enhancement of the auroral 
precipitation [26]. In addition, the TEC enhancement at the polar wall of the trough during the main phase was located in the quiet-time mid-latitude trough region around $61^{\circ} \mathrm{N}$. Thus, the positive ionospheric storm effect at the polar side of the trough was caused by the mechanism of energetic particle precipitation increasing the ionization in the quiet-time mid-latitude trough region around $61^{\circ} \mathrm{N}[27,28]$.

\subsection{September 2017 Storm}

\subsubsection{Geomagnetic Conditions}

The 2017 September storm with a double main phase was an intense geomagnetic storm event in solar cycle $24[29,30]$. The IMF Bz and geophysical conditions during 6-8 September 2017 are described in Figure 4. The SYM-H shows that a sudden storm commencement occurred at $\sim 00$ UT on 7 September 2017 (Figure 4d). The initial phase occurred after $\sim 00$ UT. The AE index reached $\sim 1400$ nT close to 09:07 UT (Figure 4b), indicating the occurrence of strong geomagnetic activity. The SYM-H shows two main phases on 7 and 8 September (Figure $4 d$ ). The first main phase began at 20:37 UT, as the SYM-H (Figure 4d) began to decrease. During the first main phase of the storm, the SYM-H (Figure $4 \mathrm{~d}$ ) reached a minimum of $-144 \mathrm{nT}$. The IMF Bz (Figure $4 \mathrm{a}$ ) reached $-31.2 \mathrm{nT}$ at $\sim 23: 31$ UT on 7 September. The corresponding AE (Figure 4b) and Kp (Figure 4c) indices reached their highest magnitudes of $\sim 2447 \mathrm{nT}$ and 8 , respectively. At $\sim 02: 30$ UT on 8 September, the IMF Bz (Figure $4 \mathrm{a}$ ) turned northward. The second main phase of the storm began at 11:34 UT on 8 September, as the SYM-H (Figure $4 \mathrm{~d}$ ) began to decrease. During this second main phase of the storm, the SYM-H (Figure $4 \mathrm{~d}$ ) reached a minimum of $-122 \mathrm{nT}$. The associated AE (Figure 4b) and Kp (Figure 4c) indices reached their highest magnitudes of $\sim 2677 \mathrm{nT}$ and 8.3, respectively. The values of F10.7 (Figure 4c) were $134.9 \mathrm{sfu}$, $130.4 \mathrm{sfu}$, and $118.5 \mathrm{sfu}$ on 6-8 September, respectively.

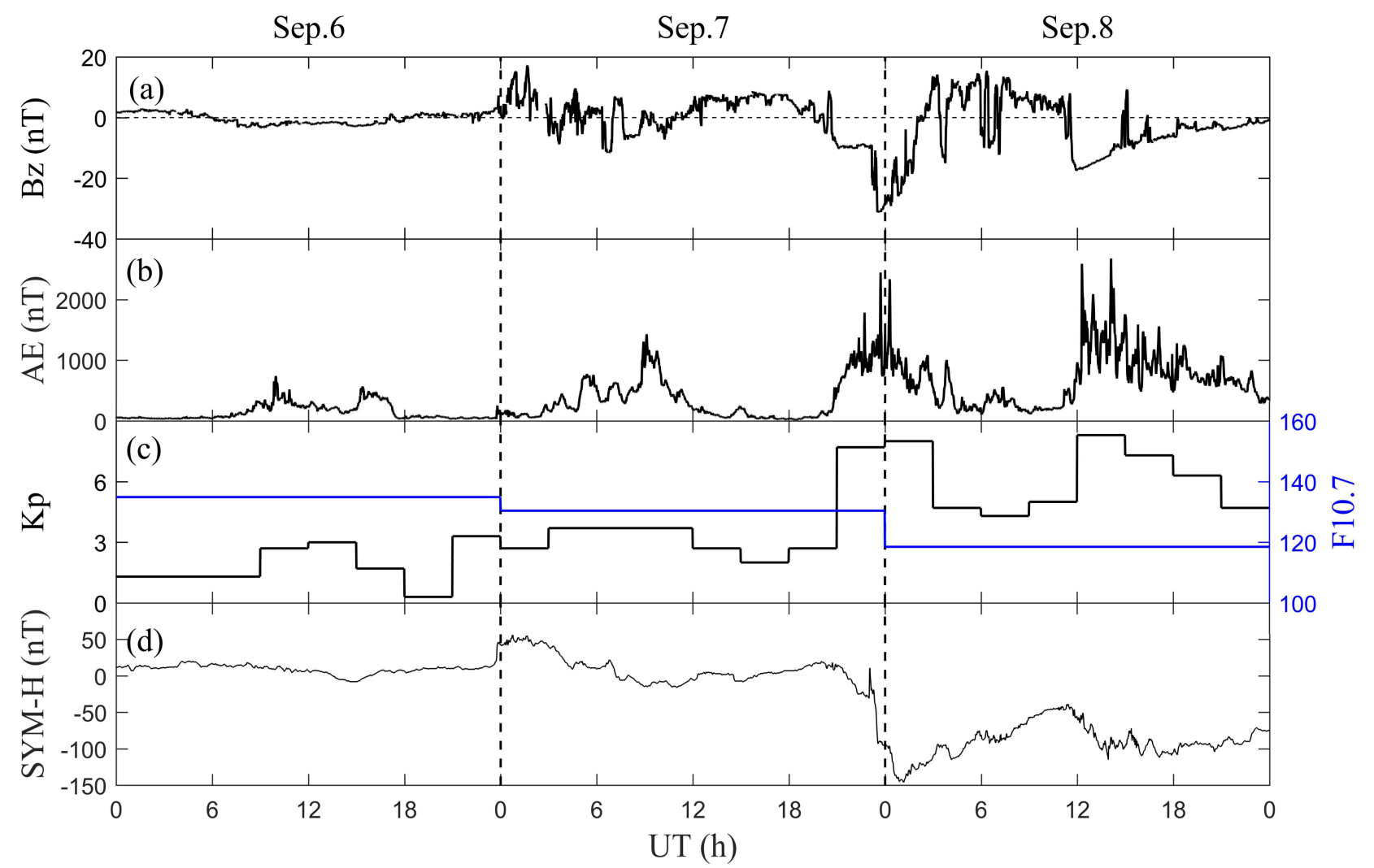

Figure 4. Time series of (a) IMF Bz, (b) AE index, (c) Kp index (dark line) and F10.7 (blue line), and (d) SYM-H index during the period of 6-8 September 2017. 


\subsubsection{Ionospheric Storm Disturbance during the 2017 September Storm}

Figure 5 shows the ionospheric storm variations for the American sector during the 2017 September storm. Figure 5a displays the TEC distribution in UT-MLAT coordinates. During the quiet day on 6 September, the trough was located at a latitudinal band of $60-62^{\circ} \mathrm{N}$, and showed a small temporal variation. The trough position changed by $2^{\circ}$ in latitude during the quiet day. The TEC value in the trough gradually decreased over time, reaching a minimum value of less than 2.5 TECU during 05-10 UT ( 00-05 LT), and then gradually increased. During the initial phase of the storm, the trough first occurred at 02 UT ( 21 LT) on 7 September, and then gradually moved to a lower latitude, from $67^{\circ} \mathrm{N}$ at $02 \mathrm{UT}(\sim 21 \mathrm{LT})$ on 7 September to $53^{\circ} \mathrm{N}$ at $11 \mathrm{UT}$ ( $\left.\sim 6 \mathrm{LT}\right)$ on 7 September with the decrease in SYM-H. The trough appeared earlier than during the quiet day. The trough position changed by $14^{\circ}$ in latitude during the initial phase of the storm, which is larger than the change during the quiet day. The TEC value in the trough during 05-10 UT (00-05 LT) was between 2.5 and 4.5 TECU—larger than during the quiet day. During the first main phase of the storm, the trough first appeared at 23 UT ( 18 LT) on 7 September, which is earlier than the time of the trough's occurrence during the quiet day. Afterwards, the trough quickly moved equatorward from $65^{\circ} \mathrm{N}$ at $23 \mathrm{UT}(\sim 18 \mathrm{LT})$ on 7 September to $50^{\circ} \mathrm{N}$ at 02 UT ( $21 \mathrm{LT})$ on 8 September with the rapid decrease in SYM-H. The equatorward movement of the trough stopped at 02 UT on 8 September; after that, the trough returned to higher latitude with a large disturbance, and disappeared at 10 UT ( 05 LT) on 8 September. During this period, the trough position changed by $15^{\circ}$ in latitude, which is larger than the change during the quiet day. It can be seen that the temporal variation in the trough position changed significantly during the storm. The TEC value in the trough gradually decreased with time, reaching a minimum of less than 2.5 TECU during 07-09 UT on 8 September, and then increased. During the second main phase of the storm, the trough did not occur, because it was daytime.

Figure $5 b$ shows the TEC absolute deviations from the reference during the 2017 September storm. During the initial phase of the storm, the absolute deviation value of TEC was positive (indicated by yellow) at mid- and high latitudes. The positive value at the polar side of the trough was slightly larger than that at the equatorward side of the trough, and the positive value around the trough position was slightly smaller than that at both sides of the trough. The absolute deviation value of TEC at the equatorward side of the trough gradually decreased as time progressed. The larger enhancement of TEC at the polar side of the trough can be attributed to enhanced energetic particle precipitation represented by a large AE value [3,26-28]. The smaller enhancement of TEC around the trough position is partly associated with the trough. The effect of the storm-associated equatorward shift of the trough on the mid-latitude ionosphere was overpowered by the positive storm due to the disturbance wind effect [31-35]. During the first main phase of the storm, the absolute deviation value of TEC around the trough position was negative (indicated by blue) from 23 UT on 7 September to 01 UT on 8 September, and nearly zero (indicated by white) during the first recovery phase of the storm (02-10 UT on 8 September). The absolute deviation value of TEC at both sides of the trough was positive from 23 UT on 7 September to 06 UT on 8 September. After 06 UT on 8 September, the absolute deviation value of TEC was negative at the equatorward side of the trough, whereas the absolute deviation value of TEC remained positive at the polar side of the trough. The negative ionospheric storm effect around the trough position during the first main phase of the storm was clearly related to the occurrence and movement of the trough. The negative ionospheric storm effect caused by the trough was transmitted to lower latitudes through the equatorward movement of the trough. The TEC was unchanged around the trough position during the first recovery phase; this may be related to the storm-associated trough displacement. In addition, the unchanged TEC may also be associated with auroral ionization [36,37]. The combination of these factors causes the TEC value in the trough during the first recovery phase to be very close to the local TEC value during the quiet day. Overall, the absolute deviation value of 
TEC was negative in daytime during the second main phase. No obvious trough occurred during the second main phase.
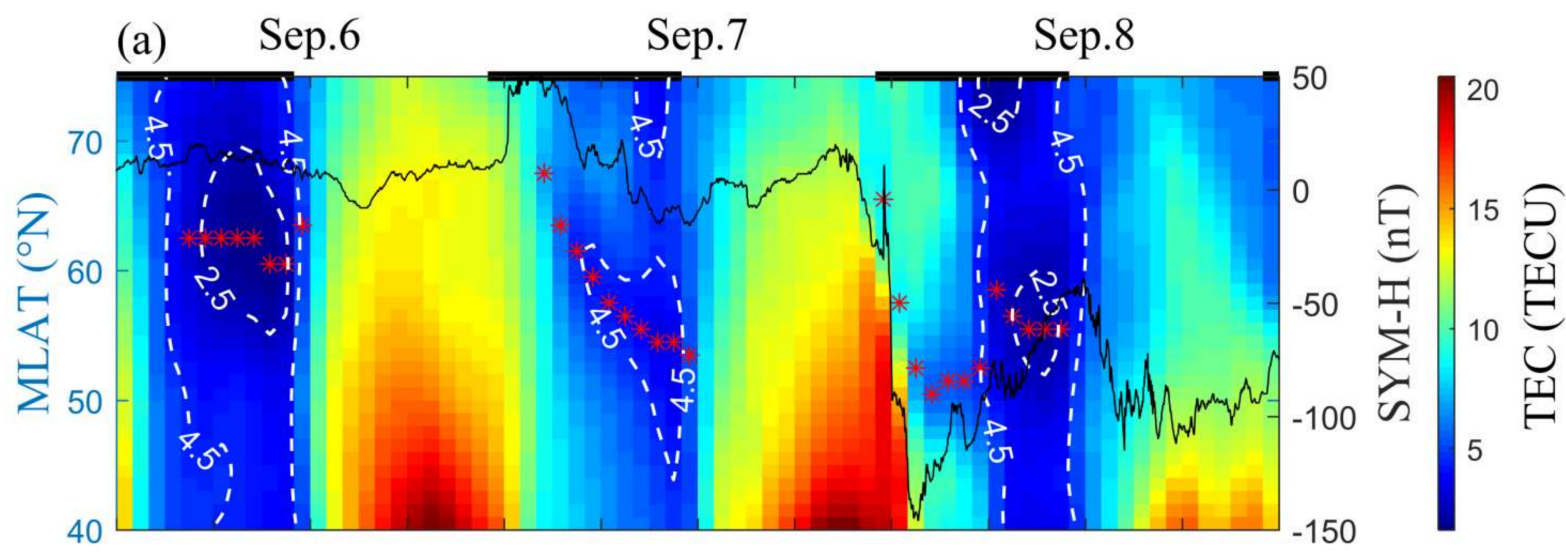

(b)

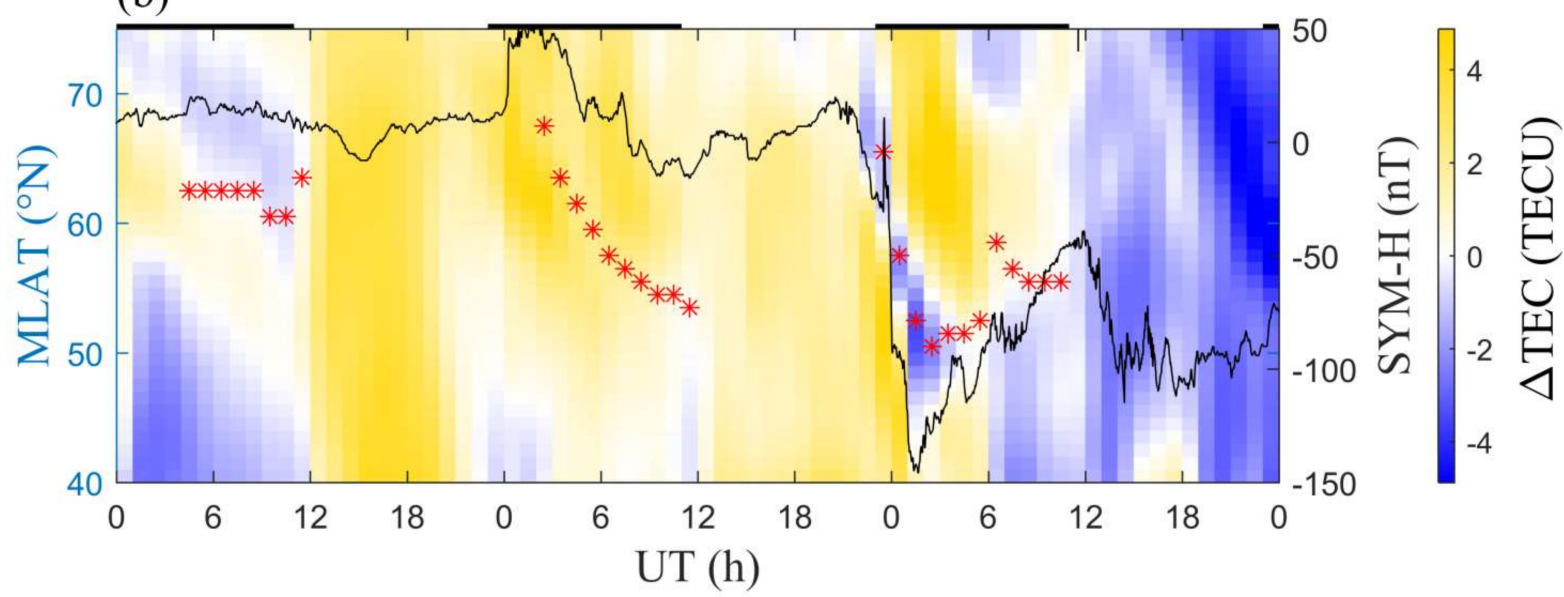

Figure 5. Ionospheric storm variations of (a) TEC and (b) TEC absolute deviations from the reference for the American sector during the 2017 September storm. The contour levels indicate the 2.5 and 4.5 TECU values. The red asterisks indicate the mid-latitude trough position. The black line shows the SYM-H variations. The local nighttime in the American sector is marked with thick black line segments.

\subsection{March 2015 Storm}

\subsubsection{Geomagnetic Conditions}

The 2015 March storm, also known as the St. Patrick's Day storm, was the largest geomagnetic storm in solar cycle 24 [38]. The IMF Bz and geophysical conditions during 16-18 March 2015 are described in Figure 6. At 04:45 UT on 17 March, the SYM-H (Figure 6d) increased abruptly, indicating the storm's sudden commencement (SSC). The main phase of the storm began at 06:00 UT on 17 March, as the SYM-H (Figure 6d) began to decrease. After that, the SYM-H (Figure 6d) gradually decreased, with two minima of $-100 \mathrm{nT}$ around $10 \mathrm{UT}$ and $-233 \mathrm{nT}$ around $23 \mathrm{UT}$ on $17 \mathrm{March}$, indicating the end of the main phase. The IMF Bz turned northward at 09:30 UT on 17 March and $~ 00$ UT on 18 March (Figure 6a). During the main phase of the storm, the AE (Figure $6 \mathrm{~b}$ ) and Kp (Figure $6 \mathrm{c}$ ) indices increased to more than $2000 \mathrm{nT}$ and 7, respectively. After 23 UT on 17 March, the SYM-H (Figure 6d) gradually recovered, with a very long recovery phase. The values of F10.7 (Figure 6c) were $116 \mathrm{sfu}, 113.2 \mathrm{sfu}$, and $113.7 \mathrm{sfu}$ on 16-18 March, respectively. 


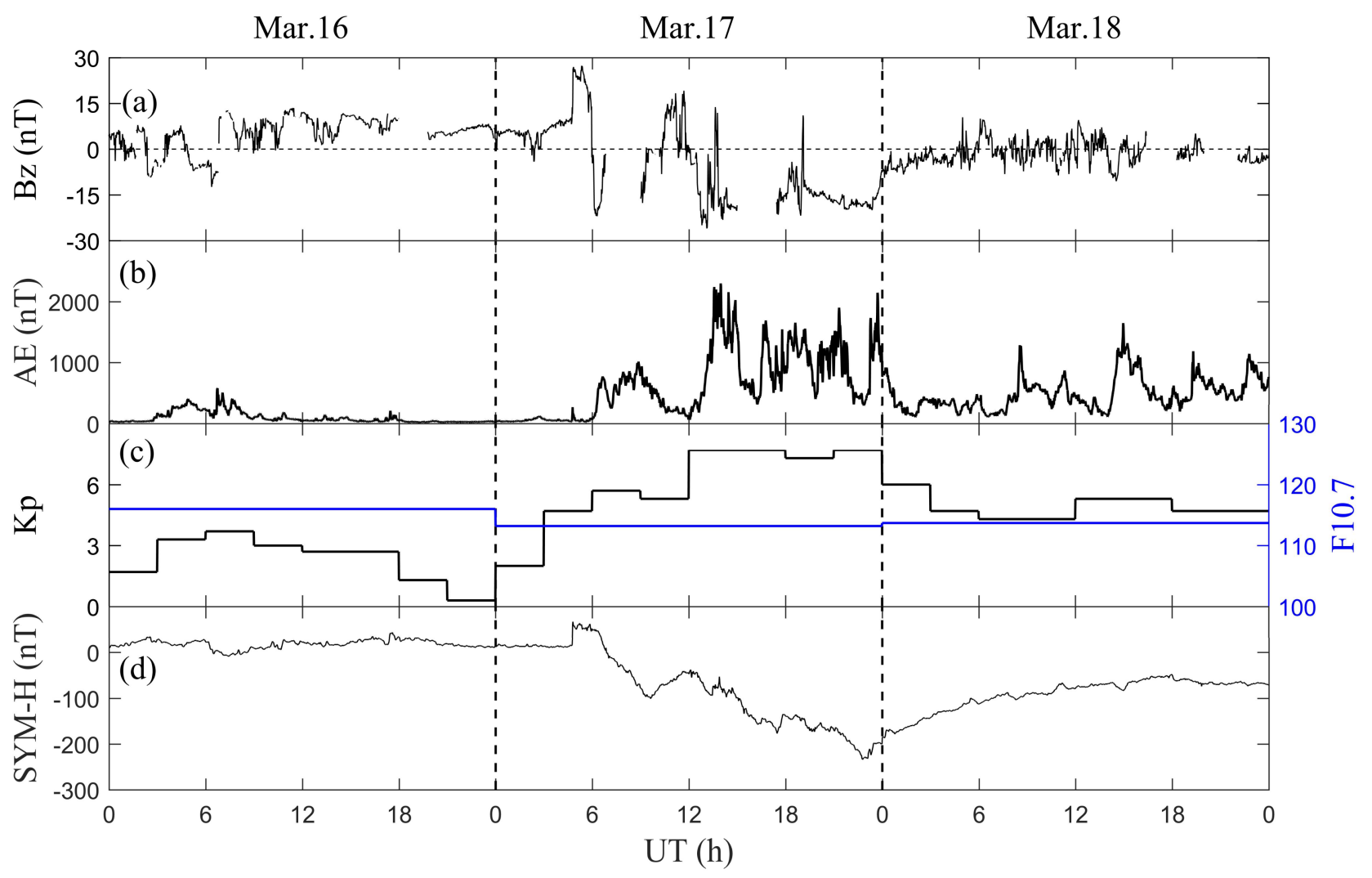

Figure 6. Time series of (a) IMF Bz, (b) AE index, (c) Kp index (dark line) and F10.7 (blue line), and (d) SYM-H index during the period of 16-18 March 2015.

\subsubsection{Ionospheric Storm Disturbance during the 2015 March Storm}

The ionospheric storm variations for the American sector during the 2015 March storm are shown in Figure 7. The TEC distribution in UT-MLAT coordinates is displayed in Figure 7a. During the quiet day, the trough first appeared at $04 \mathrm{UT}(\sim 23 \mathrm{LT})$ and $61^{\circ} \mathrm{N}$. After that, the trough moved equatorward from $61^{\circ} \mathrm{N}$ at $05 \mathrm{UT}$ to $58^{\circ} \mathrm{N}$ at $08 \mathrm{UT}$ with the decrease in SYM-H, and then gradually moved to higher latitude with the increase in SYM-H. During this period, the trough position changed by $3^{\circ}$ in latitude. The TEC value in the trough gradually decreased with time, reaching a minimum value of less than 6 TECU during 06-10 UT ( 01-05 LT), and then gradually increased. During 17 March-the day of the storm - the trough first appeared at $03 \mathrm{UT}(\sim 22 \mathrm{LT})$ and $64^{\circ} \mathrm{N}$, and then sharply moved equatorward from $63^{\circ} \mathrm{N}$ at $04 \mathrm{UT}$ to $50^{\circ} \mathrm{N}$ at $09 \mathrm{UT}$ with the rapid decrease in SYM-H. The equatorward movement of the trough stopped at 09 UT on 17 March; afterwards, the trough remained at $50^{\circ} \mathrm{N}$ until $12 \mathrm{UT}$. After $12 \mathrm{UT}$, the trough returned to $52^{\circ} \mathrm{N}$ at $13 \mathrm{UT}$, and disappeared thereafter. The trough position changed by $14^{\circ}$ in latitude, which is larger than the change during the quiet day. The TEC value in the trough was mainly between 6 and 8 TECU during 03-10 UT (22-05 LT) on 17 March, and increased to more than 8 TECU after 10 UT on 17 March. The TEC value in the trough during 06-10 UT (01-05 LT) on 17 March was larger than those at the same times during the quiet day. During the recovery phase of the storm, the trough first appeared at $54^{\circ} \mathrm{N}$ and $22 \mathrm{UT}$ ( 17 LT) on 17 March, which is earlier than it appeared during the quiet day. The equatorward movement of the trough stopped at $00 \mathrm{UT}$ on $18 \mathrm{March}$; afterwards, the trough remained at $\sim 51^{\circ} \mathrm{N}$ till $05 \mathrm{UT}$ on 18 March, and then gradually moved poleward from $51^{\circ} \mathrm{N}$ at $05 \mathrm{UT}$ to $59^{\circ} \mathrm{N}$ at $11 \mathrm{UT}$ on 18 March with the increase in SYM-H. During this period, the trough position changed by $8^{\circ}$ in latitude. The TEC value in the trough gradually decreased from more than 8 TECU at 22 UT on 17 March to less than 4 TECU between 04 UT and 11 UT on 18 March. 

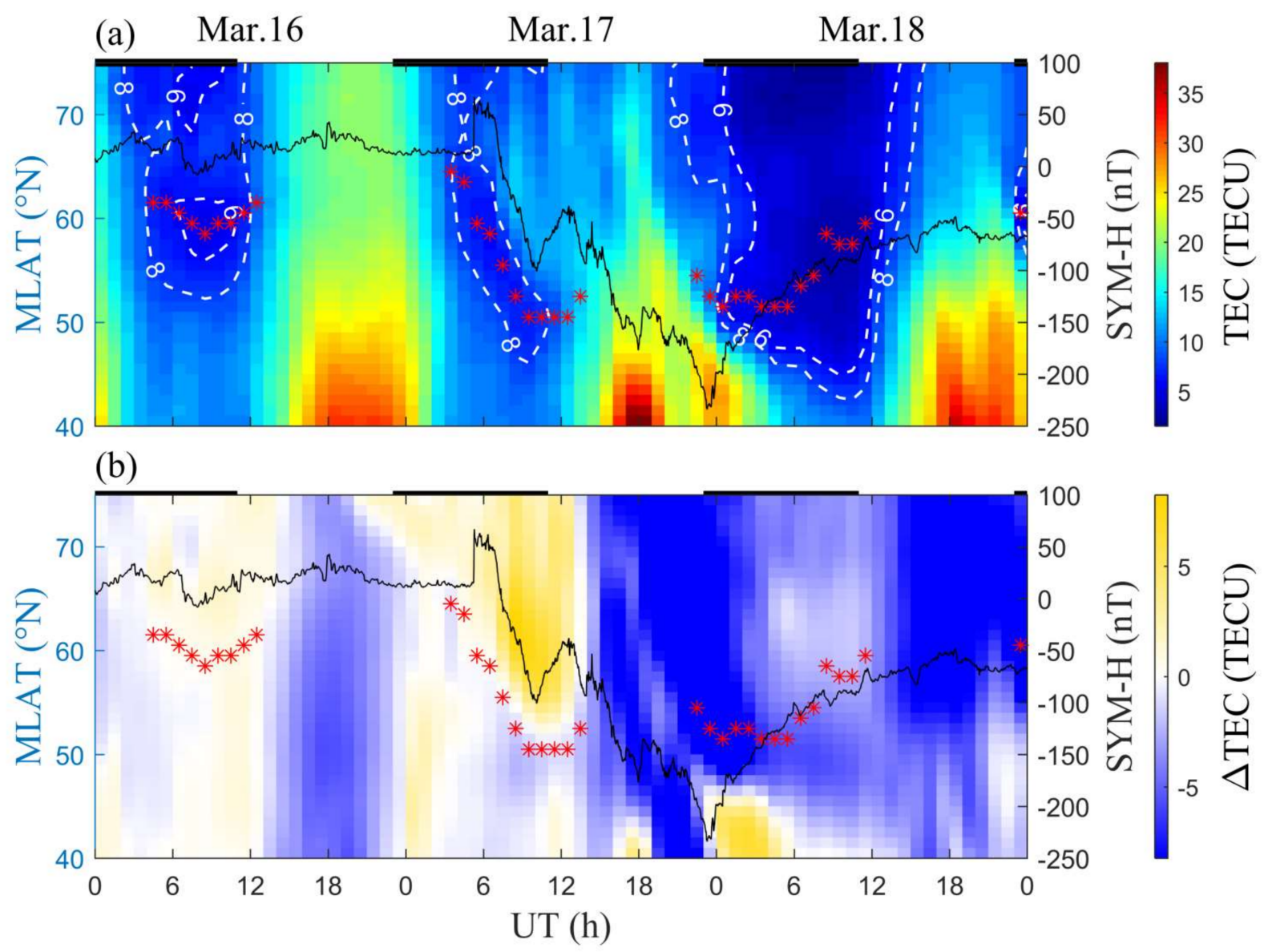

Figure 7. Ionospheric storm variations of (a) TEC and (b) TEC absolute deviations from the reference for American sector during the 2015 March storm. The contour levels indicate the 4, 6, and 8 TECU values. The red asterisks indicate the mid-latitude trough position. The black line shows the SYM-H variations. The local nighttime in the American sector is marked with thick black line segments.

Figure $7 \mathrm{~b}$ shows the TEC absolute deviations from the reference during the 2015 March storm. After the onset of the SSC at 04:45 UT on 17 March, the absolute deviation value of TEC was positive (indicated by yellow) at the polar side of the trough, and negative (indicated by blue) around the trough position and at the equatorward side of the trough. The negative ionospheric storm effect at latitudes between $40^{\circ} \mathrm{N}$ and $45^{\circ} \mathrm{N}$ disappeared during the period of 11-15 UT. The positive ionospheric storm effect at the polar side of the trough can be attributed to the mechanism by which energetic particle precipitation increases the ionization in the quiet-time trough region around $60^{\circ} \mathrm{N}[3,26-28]$. The negative ionospheric storm effect around the trough position and at the equatorward side of the trough covers a wide latitude range, and is not limited to the area of the trough; thus, the negative ionospheric storm effect is not related to the trough. The negative ionospheric storm effect has also been well explained through the variation of the neutral composition by Astafyeva et al. [22]. Compared with the negative ionospheric storm effect induced by the neutral composition changes, the effect of the storm-associated equatorward displacement of the trough on the mid-latitude ionosphere can be negligible. During the recovery phase of the storm, there are negative absolute deviations of TEC at all latitudes between $40^{\circ} \mathrm{N}$ and $75^{\circ} \mathrm{N}$ (indicated by blue), with the exception of positive values at latitudes between $40^{\circ} \mathrm{N}$ and $46^{\circ} \mathrm{N}$ during the period of 00-06 UT on $18 \mathrm{March}$. This negative storm is also explained through the variation of the neutral composition by Astafyeva et al. [22]. Compared with the negative ionospheric storm effect induced by the neutral composition 
changes, the effect of the storm-associated displacement of the trough on the mid-latitude ionosphere can be negligible during the recovery phase of the storm.

\section{Discussion}

During the three intense geomagnetic storms, the temporal variation of the trough position in the night sector changed significantly as compared with that during the quiet day. The temporal variation of the trough position in the night sector differs essentially from one storm to another. During the quiet day, the temporal variation of the trough position in the night sector for the American sector is actually its local time variation. However, the temporal variation of the trough position in the night sector during geomagnetic storms is mainly associated with the temporal variation of the geomagnetic activity. The temporal variation of the trough position during geomagnetic storms is consistent with the temporal variation of the SYM-H. The trough position moves equatorward with the decrease in SYM-H, and poleward with the increase in SYM-H. During the initial and main phases of the storm, the trough appears earlier as compared with that during the quiet day. During this period, the trough sharply moves equatorward from the quiet-time subauroral latitude to mid-latitude with the decrease in SYM-H. The trough moved equatorward by around $20^{\circ}, 15^{\circ}$, and $14^{\circ}$ during the main phases of the storms on 26 August 2018, 8 September 2017, and 17 March 2015, respectively. The movements were larger than those during the quiet day and the statistical results [20,39]. The trough stopped moving near the minima of SYM-H, accompanied by the northward turning of IMF Bz (Figures 2, 4 and 6). The northward turning of IMF Bz can usually induce an eastward perturbed electric field at nighttime [40]. The eastward perturbed electric field can uplift the ionosphere and further lead to positive TEC changes at lower latitudes [41]. The positive TEC changes can stop the equatorward movement of the trough. The relationship between the trough and the perturbed electric field can be further examined in the future. During the early recovery phase of the storm, the trough also appears earlier than during the quiet day. The trough moves poleward with the increase in SYM-H.

During the three intense geomagnetic storms, the temporal variation of TEC values in the trough was similar to that during the quiet day. The TEC value in the trough first gradually decreased with time, and then increased in the morning region. The temporal variation of TEC values in the trough are mainly consistent with the previous statistical results $[5,42,43]$. The TEC value in the trough was larger during 03-10 UT ( 22-05 LT) on the storm day of 26 August 2018, during 05-10 UT (00-05 LT) on the storm day of 7 September 2017, and during 06-10 UT (01-05 LT) on the storm day of 17 March 2015, compared to the values at the same times during the quiet day. The larger TEC value in the trough is due to the trough being infilled by the auroral ionization region, which shifts equatorward during the initial phase and main phase of the three geomagnetic storms [36,37].

During the three intense geomagnetic storms, the levels of geomagnetic activity caused variations in the trough position and the TEC values in the trough. Simultaneously, the equatorward displacement of the trough can lead to ionospheric variation. During the three intense geomagnetic storms, the behavior of ionospheric variation in the area of the trough showed both commonalities and differences. The ionospheric behavior at the polar side of the trough displayed the same positive ionospheric storm effect during the initial and main phases of the three geomagnetic storms. The positive ionospheric storm effect is associated with the mechanism by which energetic particle precipitation increases the ionization in the quiet-time trough region [3,26-28].

The ionospheric behavior at the equatorward side of the trough showed different ionospheric storm effects during the three geomagnetic storms. The ionospheric behavior at the equatorward side of the trough displayed a positive ionospheric storm effect during the main phase of the 2018 August storm and during the initial phase of the 2017 September storm, a positive ionospheric storm effect followed by a negative ionospheric storm effect during the first main phase and first recovery phase of the 2017 September storm, and a 
negative ionospheric storm effect during the main and recovery phases of the 2015 March storm. These ionospheric storm effects cover a wide latitude range at the equatorward side of the trough.

The ionospheric behavior around the trough position also showed different ionospheric storm effects during the three geomagnetic storms. Ionospheric behavior around the trough position differs essentially from one storm to another. Ionospheric behavior around the trough position displayed a negative ionospheric storm effect during the main phases of the three geomagnetic storms and the recovery phase of the 2015 March storm, unchanged ionospheric behavior during the first recovery phase of the 2017 September storm, and a positive ionospheric storm effect during the initial phase of the 2017 September storm.

During the main phases of the 2018 August storm and 2017 September storm, the ionospheric behavior around the trough position was dominated by the striking negative ionospheric storm effect. The negative ionospheric storm effect was limited to the narrow area of the trough and transmitted to other regions with the equatorward displacement of the trough. The negative ionospheric storm effect is related to the storm-associated equatorward displacement of the trough. In the mid-latitude ionosphere, this kind of negative ionospheric storm effect produced by the trough is different from that produced by other mechanisms, such as subauroral polarization streams (SAPs) and neutral composition disturbance. The negative ionospheric storm effect caused by the storm-associated equatorward displacement of the trough is limited to the narrow area of the trough, whereas the negative ionospheric storm effect caused by neutral composition disturbance usually covers a wider latitude range due to the transportation of the equatorward storm-induced winds [44]. In addition, the negative ionospheric storm effect produced by the development of SAPs is limited to the SAPs region and in the pre-midnight sector [12,45]. During the main phase and recovery phase of the 2015 March storm, the ionospheric behavior around the trough position was also dominated by the negative ionospheric storm effect. Unlike the main phases of the 2018 August storm and 2017 September storm, the negative ionospheric storm effect during the main phase and recovery phase of the 2015 March storm was not limited to the narrow area of the trough, but covered a wide latitude range. The negative ionospheric storm effect has been attributed to the variation of the neutral composition by Astafyeva et al. [22]. During the 2015 March storm, the effect of the mid-latitude trough on the mid-latitude ionosphere was negligible compared with the negative ionospheric storm effect induced by neutral composition disturbance. Thus, it is demonstrated that the negative ionospheric storm effect around the trough position during geomagnetic storms is not always associated with the equatorward expansion of the trough.

During the first recovery phase of the 2017 September storm, the ionospheric behavior around the trough position showed no significant changes. The TEC value in the trough was very close to the quiet-time level. The unchanged ionospheric behavior was limited to the narrow area of the trough, and was transmitted to other regions with the displacement of the trough. This unchanged ionospheric behavior around the trough position is associated with the storm-associated displacement of the trough and auroral ionization [36,37].

During the initial phase of the 2017 September storm, the ionospheric behavior around the trough position displayed a positive ionospheric storm effect. The positive ionospheric storm effect was also seen at both sides of the trough, and covered a wide latitude range. However, the positive ionospheric storm effect around the trough position was slightly smaller than that at both sides of the trough. It is clear that the effect of the storm-associated equatorward displacement of the trough on the mid-latitude ionosphere was overpowered by the positive ionospheric storm effect. Thus, it is also demonstrated that the equatorward movement of the trough during geomagnetic storms is not always accompanied by a negative ionospheric storm effect.

\section{Conclusions}

In this study, MIT TEC data were employed to study the trough characteristics and the effects of the equatorward displacement of the trough on the mid-latitude ionosphere 
during three intense geomagnetic storms in solar cycle 24. Our findings demonstrate that the equatorward movement of the trough during geomagnetic storms is not always accompanied by a negative ionospheric storm effect (e.g., the positive ionospheric storm effect during the initial phase of the 2017 September storm). We also found that the negative ionospheric storm effect around the trough position during geomagnetic storms is not always associated with the equatorward movement of the trough (e.g., the negative ionospheric storm effect during the main phase of the 2015 March storm was associated with the neutral composition disturbance). The following conclusions can be drawn:

(1) The temporal variation of the trough position in the night sector differs essentially from one storm to another. The temporal variation of the trough position in the night sector during geomagnetic storms is mainly related to the temporal variation of the geomagnetic activity. During geomagnetic storms, the trough appears earlier as compared with that during quiet days. The trough position moved equatorward by around $20^{\circ}, 15^{\circ}$, and $14^{\circ}$ for the storms on 26 August 2018, 8 September 2017, and 17 March 2015 respectively. The movements were larger than the statistical results. The trough stopped moving near the minima of SYM-H, accompanied by the northward turning of IMF Bz;

(2) During the three intense geomagnetic storms, the temporal variation of the TEC value in the trough was similar to that during the quiet day. However, the TEC value in the trough during the initial phase and main phase of the three geomagnetic storms was larger than that during the quiet day;

(3) During the three intense geomagnetic storms, the ionospheric behavior around the trough position displayed a negative ionospheric storm effect during the main phases of the three geomagnetic storms and the recovery phase of the 2015 March storm, unchanged ionospheric behavior during the first recovery phase of the 2017 September storm, and a positive ionospheric storm effect during the initial phase of the 2017 September storm. The negative ionospheric storm effect around the trough position during the main phases of the 2018 August storm and 2017 September storm, as well as the unchanged ionospheric behavior around the trough position during the first recovery phase of the 2017 September storm, are associated with the stormassociated displacement of the trough. These ionospheric storm effects around the trough position produced by the trough are limited to the narrow area of the trough, and are transmitted to other regions with the displacement of the trough. However, the rest of the ionospheric storm effects around the trough position are not limited to the narrow area of the trough, and cover a wide latitude range; these ionospheric storm effects are not caused by the trough.

Author Contributions: N.Y. and T.Y. conceived the ideas, performed the data analyses, and wrote the manuscript; H.L., L.L., Y.-Y.S., X.Y. and J.W. contributed significantly to analysis and manuscript preparation; C.X., X.Z. and G.H. helped to perform the analysis with constructive discussions. All authors have read and agreed to the published version of the manuscript.

Funding: This research was supported by the National Natural Science Foundation of China (41904142, 41822403, 41774165), the National Key Research and Development Program (2017YFE0131400), the Postdoctoral Innovation Project of Hubei Province (1232035), the B-type Strategic Priority Program of the Chinese Academy of Sciences (XDB41000000), and the Youth Innovation Promotion Association CAS.

Institutional Review Board Statement: Not applicable.

Informed Consent Statement: Not applicable.

Data Availability Statement: The MIT TEC data is available at http:/ / cedar.openmadrigal.org/ (accessed on 1 November 2021). The SYM-H index, IMF Bz, Kp index, and solar flux index F10.7 data are available at http:/ / omniweb.gsfc.nasa.gov (accessed on 1 November 2021). The AE geomagnetic activity index data is available at http:/ / wdc.kugi.kyoto-u.ac.jp / (accessed on 1 November 2021). 
Acknowledgments: The authors gratefully acknowledge MIT Haystack's Madrigal database mirror site at the Institute of Geology and Geophysics, Chinese Academy Sciences (http://cedar. openmadrigal.org/ (accessed on 1 November 2021)), for MIT TEC data.

Conflicts of Interest: The authors declare no conflict of interest.

\section{References}

1. Muldrew, D.B. F-layer ionization troughs deduced from Alouette data. J. Geophys. Res. 1965, 70, 2635-2650. [CrossRef]

2. Rodger, A.S.; Moffett, R.J.; Quegan, S. The role of ion drift in the formation of ionisation troughs in the mid- and high-latitude ionosphere-A review. J. Atmos. Terr. Phys. 1992, 54, 1-30. [CrossRef]

3. Rodger, A. The Mid-Latitude trough: Revisited, in Midlatitude Ionospheric Dynamics and Disturbances; Geophysical Monograph Series; Kintner, P.M., Jr., Coster, A.J., Fuller-Rowell, T., Mannucci, A.J., Mendillo, M., Heelis, R., Eds.; AGU: Washington, DC, USA, 2008; Volume 181, pp. 25-33.

4. He, M.; Liu, L.; Wan, W.; Zhao, B. A study on the nighttime midlatitude ionospheric trough. J. Geophys. Res. 2011, 116, A05315. [CrossRef]

5. Yang, N.; Le, H.; Liu, L. Statistical analysis of ionospheric mid-latitude trough over the Northern Hemisphere derived from GPS total electron content data. Earth Planets Space 2015, 67, 196. [CrossRef]

6. Castaño, J.M.; Natali, M.P.; Meza, A. Postmidnight mid-latitude ionospheric trough position oscillations during solar cycle 24. Adv. Space Res. 2021, 68, 1876-1889. [CrossRef]

7. Prölss, G.W.; Brace, L.H.; Mayr, H.G.; Carignan, G.R.; Killeen, T.L.; Klobuchar, J.A. Ionospheric storm effects at subauroral latitudes: A case study. J. Geophys. Res. 1991, 96, 1275-1288. [CrossRef]

8. Deminov, M.G.; Karpachev, A.T.; Annakuliev, S.K.; Afonin, V.V.; Smilauer, Y. Dynamics of the ionization troughs in the night-time subauroral F-region during geomagnetic storms. Adv. Space Res. 1996, 17, 141-145. [CrossRef]

9. Shinbori, A.; Otsuka, Y.; Tsugawa, T.; Nishioka, M.; Kumamoto, A.; Tsuchiya, F.; Matsuda, S.; Kasahara, Y.; Matsuoka, A.; Ruohoniemi, J.M.; et al. Temporal and spatial variations of storm time midlatitude ionospheric trough based on global GNSS-TEC and Arase satellite observations. Geophys. Res. Lett. 2018, 45, 7362-7370. [CrossRef]

10. Blagoveshchensky, D.V.; Lester, M.; Kornienko, V.A.; Shagimuratov, I.I.; Stocker, A.J.; Warrington, E.M. Observations by the CUTLASS radar, HF Doppler, oblique ionospheric sounding, and TEC from GPS during a magnetic storm. Ann. Geophys. 2005, 23, 1697-1709. [CrossRef]

11. Galav, P.; Rao, S.S.; Sharma, S.; Gordiyenko, G.; Pandey, R. Ionospheric response to the geomagnetic storm of 15 May 2005 over midlatitudes in the day and night sectors simultaneously. J. Geophys. Res. Space Phys. 2014, 119, 5020-5031. [CrossRef]

12. Horvath, I.; Lovell, B.C. Positive and negative ionospheric storms occurring during the 15 May 2005 geomagnetic superstorm. J. Geophys. Res. Space Phys. 2015, 120, 7822-7837. [CrossRef]

13. Nayak, C.; Tsai, L.-C.; Su, S.-Y.; Galkin, I.A.; Tan, A.T.K.; Nofri, E.; Jamjareegulgarn, P. Peculiar features of the low-latitude and midlatitude ionospheric response to the St. Patrick's Day geomagnetic storm of 17 March 2015. J. Geophys. Res. Space Phys. 2016, 121, 7941-7960. [CrossRef]

14. Liu, Y.; Li, Z.; Fu, L.; Zhang, C. Studying the ionospheric responses induced by a geomagnetic storm in September 2017 with multiple observations in America. GPS Solut. 2020, 24, 3. [CrossRef]

15. Danilov, A.D. Ionospheric f-region response to geomagnetic disturbances. Adv. Space Res. 2013, 52, 343-366. [CrossRef]

16. Huo, X.; Yuan, Y.; Ou, J.; Li, Z.; Wang, N. A new ionospheric tomographic algorithm taking into account the variation of the ionosphere. Chin. J. Geophys. Chin. Ed. 2016, 59, 2393-2401.

17. Zhang, W.; Huo, X.; Yuan, Y.; Li, Z.; Wang, N. Algorithm Research Using GNSS-TEC Data to Calibrate TEC Calculated by the IRI-2016 Model over China. Remote Sens. 2021, 13, 4002. [CrossRef]

18. Langley, R.B. Propagation of the GPS signals. In GPS for Geodesy; Kleusberg, A., Teunissen, P., Eds.; Springer: Berlin/Heidelberg, Germany; New York, NY, USA, 1996; pp. 103-140.

19. Rideout, W.; Coster, A. Automated GPS processing for global total electron content data. GPS Solut. 2006, 10, 219-228. [CrossRef]

20. Yang, N.; Le, H.; Liu, L. Statistical analysis of the midlatitude trough position during different categories of magnetic storms and different storm intensities. Earth Planets Space 2016, 68, 171. [CrossRef]

21. Le, H.; Yang, N.; Liu, L.; Chen, Y.; Zhang, H. The latitudinal structure of nighttime ionospheric TEC and its empirical orthogonal functions model over North American sector. J. Geophys. Res. Space Phys. 2017, 122, 963-977. [CrossRef]

22. Astafyeva, E.; Zakharenkova, I.; Förster, M. Ionospheric response to the 2015 St. Patrick's Day storm: A global multi-instrumental overview. J. Geophys. Res. Space Phys. 2015, 120, 9023-9037. [CrossRef]

23. Vanlommel, P. Solar-Terrestrial Centre of Excellence (STCE) Newsletter, 20-26 August 2018. Available online: http:/ / www.stce. be/newsletter/pdf/2018/STCEnews20180831.pdf (accessed on 1 December 2021).

24. Li, Q.; Huang, F.; Zhong, J.; Zhang, R.; Kuai, J.; Lei, J.; Liu, L.; Ren, D.; Ma, H.; Yoshikawa, A.; et al. Persistence of the long-duration daytime TEC enhancements at different longitudinal sectors during the August 2018 geomagnetic storm. J. Geophys. Res. Space Phys. 2020, 125, e2020JA028238. [CrossRef]

25. Schunk, R.W.; Banks, P.M.; Raitt, W.J. Effects of electric fields and other processes upon the nighttime high-latitude F layer. J. Geophys. Res. 1976, 81, 3271-3282. [CrossRef] 
26. Lam, M.M.; Horne, R.B.; Meredith, N.P.; Glauert, S.A.; Moffat-Griffin, T.; Green, J.C. Origin of energetic electron precipitation $>30$ keV into the atmosphere. J. Geophys. Res. 2010, 115, A00F08. [CrossRef]

27. Zou, S.; Moldwin, M.B.; Coster, A.; Lyons, L.R.; Nicolls, M.J. GPS TEC observations of dynamics of the mid-latitude trough during substorms. Geophys. Res. Lett. 2011, 38, L14109. [CrossRef]

28. Balan, N.; Bailey, G.J.; Nair, R.B. Solar and magnetic activity effects on the latitudinal variations of nighttime tec enhancement. Ann. Geophys. 1991, 9, 120-128. [CrossRef]

29. Lei, J.; Huang, F.; Chen, X.; Zhong, J.; Ren, D.; Wang, W.; Yue, X.; Luan, X.; Jia, M.; Dou, X.; et al. Was Magnetic Storm the Only Driver of the Long-Duration Enhancements of Daytime Total Electron Content in the Asian-Australian Sector Between 7 and 12 September 2017? J. Geophys. Res. Space Phys. 2018, 123, 3217-3232. [CrossRef]

30. Li, R.; Lei, J. Responses of thermospheric mass densities to the October 2016 and September 2017 geomagnetic storms revealed from multiple satellite observations. J. Geophys. Res. Space Phys. 2021, 126, e2020JA028534. [CrossRef]

31. Liu, L.; Wan, W.; Zhang, M.-L.; Zhao, B. Case study on total electron content enhancements at low latitudes during low geomagnetic activities before the storms. Ann. Geophys. 2008, 26, 893-903.

32. Jimoh, O.; Lei, J.; Huang, F. Investigation of Daytime Total Electron Content Enhancements over the Asian-Australian Sector Observed from the Beidou Geostationary Satellite during 2016-2018. Remote Sens. 2020, 12, 3406. [CrossRef]

33. Tsagouri, I.; Belehaki, A.; Moraitis, G.; Mavromichalaki, H. Positive and negative ionospheric disturbances at middle latitudes during geomagnetic storms. Geophys. Res. Lett. 2000, 27, 3579-3582. [CrossRef]

34. Wang, W.; Lei, J.; Burns, A.G.; Solomon, S.C.; Wiltberger, M.; Xu, J.; Zhang, Y.; Paxton, L.; Coster, A. Ionospheric response to the initial phase of geomagnetic storms: Common features. J. Geophys. Res. Space Phys. 2010, 115, A07321. [CrossRef]

35. Lei, J.; Wang, W.; Burns, A.G.; Solomon, S.C.; Richmond, A.D.; Wiltberger, M.; Goncharenko, L.P.; Coster, A.; Reinisch, B.W Observations and simulations of the ionospheric and thermospheric response to the December 2006 geomagnetic storm: Initial phase. J. Geophys. Res. 2008, 113, A01314. [CrossRef]

36. Karpachev, A.T. The dependence of the main ionospheric trough shape on longitude, altitude, season, local time, and solar and magnetic activity. Geomag. Aeron. 2003, 43, 239-251.

37. Buonsanto, M.J. Ionospheric storms-a review. Space Sci. Rev. 1999, 88, 563-601. [CrossRef]

38. Kuai, J.; Liu, L.; Liu, J.; Sripathi, S.; Zhao, B.; Chen, Y.; Le, H.; Hu, L. Effects of disturbed electric fields in the low-latitude and equatorial ionosphere during the 2015 St. Patrick's Day storm. J. Geophys. Res. Space Phys. 2016, 121, 9111-9126. [CrossRef]

39. Karpachev, A.T. Dynamics of main and ring ionospheric troughs at the recovery phase of storms/substorms. J. Geophys. Res. Space Phys. 2021, 126, e2020JA028079. [CrossRef]

40. Spiro, R.W.; Wolf, R.A.; Fejer, B.G. Penetration of high latitude electric fields effects to low latitudes during SUNDIAL 1984. Ann. Geophys. 1988, 6, 39-50.

41. Kelley, M.C. The Earth's Ionosphere: Plasma Physics and Electrodynamics; Elsevier: London, UK, 2009.

42. Pryse, S.E.; Kersley, L.; Malan, D.; Bishop, G.J. Parameterization of the main ionospheric trough in the European sector. Radio Sci. 2006, 41, RS5S14. [CrossRef]

43. Liu, Y.; Xiong, C. Morphology evolution of the mid-latitude ionospheric trough in nighttime under geomagnetic quiet conditions J. Geophys. Res. Space Phys. 2020, 125, e27361. [CrossRef]

44. Fuller-Rowell, T.J.; Rees, D. A three-dimensional simulation of the global dynamical response of the thermosphere to a geomagnetic substorm. J. Atmos. Terr. Phys. 1981, 43, 701. [CrossRef]

45. Wang, W.; Talaat, E.R.; Burns, A.G.; Emery, B.; Hsieh, S.; Lei, J.; Xu, J. Thermosphere and ionosphere response to subauroral polarization streams (SAPS): Model simulations. J. Geophys. Res. 2012, 117, A07301. [CrossRef] 